\title{
COVID-19 in eastern Emilia: an unusual epidemiology in Northern Italy
}

\author{
Journal of Medical Clinical Case Reports
}

Case Report

Marco Libanore $^{1 *}$, Daniela Segala ${ }^{2}$, Enrico Biagi ${ }^{3}$, Rosario Cultrera ${ }^{4}$, Laura Sighinolfi ${ }^{5}$

\author{
1, 2, 3, 4 \&5 Department Infectious Diseases St. Anna Hospital \\ and University, Ferrara (Italy); Via A. Moro n.8, 44124 \\ Cona, Ferrara (Italy).
}

\author{
"Correspondence author \\ Marco Libanore \\ Head of Infectious Diseases Unit Teaching Hospital \\ University Hospital of Ferrara \\ Italy
}

\begin{abstract}
The Authors report the unusual epidemiological features of the COVID 19 in an area of the Northern Italy. The reasons of the lower prevalence compared to other areas are described. A set of strategies have proven successful in limiting cases.
\end{abstract}

Keywords : COVID 19, low prevalence, North-eastern Italy, containment strategies.

\section{Introduction}

The province of Ferrara is an Italian province of EmiliaRomagna with a territorial extension of $2635 \mathrm{Km} 2$ and 346,000 inhabitants. The $62 \%$ of the population is concentrated in the cities of Ferrara, Cento, Argenta and Comacchio. It borders to the north with the Veneto (province of Rovigo) and Lombardy, to the west with the province of Modena, to the south with the metropolitan area of Bologna and the province of Ravenna, to the east with the Adriatic Sea. It is the province of EmiliaRomagna with the largest extension of natural reserves and protected areas, which amount to about 40,000 hectares (more than $15 \%$ of the total area).

On February 21, 2020, the first Italian autochthonous case of COVID-19 was diagnosed at Codogno (South - East Lombardy) in a 38-year-old man with no risk factors, who developed a severe form of acute respiratory failure associated with diffuse bilateral interstitial/alveolar pneumonia. It was the beginning of Italian outbreak of SARS-CoV-2 infection [1, 2]. Simultaneously, a new cluster was documented in the area of Padua (Veneto) in North-eastern Italy, at Vò Euganeo, related to the one in Lombardy [3]. On February 23, the Rector of the University of Ferrara (Emilia Romagna) decided to suspend classes, exams and all the activities that involved physical interaction, in order to limiting the circulation of more than twenty-two thousand students, many coming from Veneto. In the following weeks, COVID-19 spread all over Northern Italy, with thousands confirmed cases and dead. Emilia Romagna was the second Italian region for diagnosed cases, ranking behind only Lombardy [4]. On March 6, the first case of COVID-19 was diagnosed in our Department of Infectious Diseases at St. Anna University Hospital in Ferrara: the patient was a 76-year-old man from Cento, a town in the Ferrara province. He was admitted in critical conditions, with a severe form of acute respiratory failure associated with bilateral interstitial pneumonia, and transferred to ICU. In our area, in the following days, COVID-19 gradually increased, testimoning viral circulation. New hospital wards were opened, like in the nearby cities where the infection had already hit days before [5]. On March 9, the Central Italian Government, in response to the growing number of infected in some areas of the country, established national lockdown, blocking circulation of the population and allowing only essential activities like food chain production, health and public transport [6]. Forty days after the onset of the Italian epidemic, the national territory was divided into 3 areas according to the infection rate : one with a high viral circulation including Northern Italy and Marche region, one intermediate from Tuscany to Apulia, and one with limited prevalence including Molise, Basilicata, Calabria and the two major islands, Sicily and Sardinia. 
Cases Study

The analysis of data showed two anomalies in the Northern Italy situation: the adjacent provinces of Ferrara and Rovigo, both characterized by a wide extension of the territory with a low population density, especially the area starting east of Po river mouth, a former marshy-malarial zone, and the presence of a high rate of thalassemia trait in citizens. Forty-eight days after the first diagnosis in our province, 882 COVID-19 cases were diagnosed, of which 488 ( 55.3\% ) still hospitalized or home isolation, 110 ( $12.5 \%)$ deceased , 284 (32.2\%) clinical / virological resolved with an infection rate of $0.25 \%$, as observed in areas with limited virus circulation like Basilicata. They were mainly concentrated in urban centers: Ferrara 210 cases $(23.8 \%)$, Argenta 181 cases $(20.5 \%)$ and Cento 90 cases (10.2\%); other centers (45.5\%). The other cities of the Emilia Romagna presented a number of COVID 19 between 1000 to 5000 cases with Piacenza on the top with $1.42 \%$ of infection rate. The $11.9 \%$ of the our cases of COVID 19 presented thalassemic trait with a prevalence of $0.31 \%$ of viral infection by SARS - CoV 2 in high endemia area for heterozygosis mediterranean anemia versus $0.25 \%$ of no endemic area $(\mathrm{P}=\mathrm{NS})$.

The phenomenon of low prevalence in our area appears related to demographic, social and economic aspects than to a presumed poor susceptibility to the virus by people living in our territory. The first five cases of COVID-19 observed in our province came from Cento, assuming that the virus was arrived in our territory from north-west, through Via Emilia, from the South Lombardy hotbed. The beginning of the lockdown on March 9, soon after the start of the epidemic in our province, certainly helped limit the infection spread in the provincial territory restricting the movement of citizens. In addition, our area is characterized by an agrarian economy and density of population of 131 inhabitants for Kmq2, 1/3 over 70 years old, no small and medium-sized industries or large distribution chains and little diffusion of youth tourism; it therefore remains outside major routes of work and tourism, especially during winter season. Also, the spread of the infection from the Veneto cluster was limited thanks to the suspension of University of Ferrara educational activities involving thousands of commuter students, of the low prevalence of the infection in the near Rovigo's district and of the screening of the venetian population with nose swabs that allowed intercepting any possible source of infection, mapping the positives cases and documenting the $3.1 \%$ of occult infection of which $46 \%$ asymptomatic [3-7].

\section{Conclusions}

In conclusion is our opinion that the distance of our area from the epicenter of the Italian outbreak, has determined the delay of the first cases of COVID-19 in our district. The concomitance of the lockdown, with social containment measures, restricting travel from, to or within the affected areas, banning cultural events, and requiring people to keep social distancing, in addition to low population density, especially in the eastern
Po Valley, determined the low prevalence of SARS-CoV-2 infection in our provincial territory. Further studies are needed in order to verify the presence of additional factors involved in the hypothetical less susceptibility of this population to COVID-19.

\section{Compliance with ethical standards}

Conflict of interest: the Authors have no conflict of interest to declare.

\section{References}

1. Epidemia di (2020) COVID 19 Aggiornamento Nazionale: 5 Maggio 2020. Task force COVID 19 del Dipartimento Malattie Infettive e Servizio di Informatica. Istituto Superiore di Sanità, Roma (Italy).

2. Coronavirus (2020) i dati dei Servizi di controllo. Ministero dell'Interno. Accessed Maggio 5, 2020.

3. Lavezzo E, Franchin E, Ciavarella C, et al (2020) Suppression of COVID 19 outbreak in the municipality of Vo', Italy, Nature 2020.

4. Boccia S, Ricciardi W (2020) Ioannidis J PA What Other Countries can learn from Italy during the COVID 19 Pandemic JAMA 1447-1448.

5. Remuzzi A, Remuzzi G (2020) COVID 19 and Italy: what next? Lancet 6736 (20): 30627-30629.

6. Government of Italy (2020) Decree of the President of the Council of Ministers 9 March 2020.

7. Moirano G, Schmid M (2020) Barone-Adesi F Short Term effects of Mitigation mesasures for the containment of the COVID 19 outbreak: an experience from Northern Italy. Disaster Med and Public Health Preparedness 119: 10.

Copyright: (C2020 Marco Libanore. This is an open-access article distributed under the terms of the Creative Commons Attribution License, which permits unrestricted use, distribution, and reproduction in any medium, provided the original author and source are credited. 